\title{
Validated HPTLC Method for Simultaneous Analysis of Pyrimethamine and Sulphadoxine in Pharmaceutical Dosage Forms
}

\author{
S. Meena ${ }^{1}$ and S. M. Sandhya ${ }^{2}$ \\ ${ }^{1}$ Department of Pharmaceutical Analysis, K.M. College of Pharmacy, Uthangudi, Madurai 625 107, Tamilnadu, India \\ ${ }^{2}$ Department of Pharmaceutical Analysis, Devaki Amma Memorial College of Pharmacy, Malappuram 673 634, Kerala, India
}

Correspondence should be addressed to S. M. Sandhya; sandhyashiji82@gmail.com

Received 25 June 2012; Revised 22 August 2012; Accepted 10 September 2012

Academic Editor: Yehia Mechref

Copyright (C) 2013 S. Meena and S. M. Sandhya. This is an open access article distributed under the Creative Commons Attribution License, which permits unrestricted use, distribution, and reproduction in any medium, provided the original work is properly cited.

A simple, specific, precise, and accurate HPTLC method for analysis of pyrimethamine (PYR) and sulphadoxine (SUL) both in bulk drugs and tablet formulation was developed and validated. The method uses haloperidol as an internal standard (IS). Chromatography was performed on TLC plates with precoated silica gel $60 \mathrm{~F}_{254}$ using chloroform-n-butanol-acetone $(6: 1.5: 2$, $\mathrm{v} / \mathrm{v} / \mathrm{v}$ ) as a mobile phase. Densitometric evaluation was performed at $254 \mathrm{~nm}$. The $R_{F}$ values were 0.27 for PYR, 0.63 for IS, and 0.75 for SUL. Linear regression analysis data for calibration plots revealed good linearity over the concentration ranges 100-500 ng per band for PYR and 2000-10000 ng per band for SUL. The method was validated for linearity, accuracy (from 98.12 to 101.24\%), precision, robustness, and specificity in accordance with ICH guidelines. The limits of detection and quantification for PYR were 14.15 and $43.07 \mathrm{ng}$ per band; for SUL, 58.37 and $152.26 \mathrm{ng}$ per band, respectively. Statistical analysis showed the method enables repeatable and selective simultaneous analysis of these drugs in tablet formulation and routine quality control of the bulk drug raw material.

\section{Introduction}

Pyrimethamine (PYR: 5-(4-cholorophenyl)-6-ethyl pyrimidine 2,4-diamine) sulphadoxine (SUL: 4-amino-N-[5,6dimethoxy-4-pyrimidinyl] benzene sulphonamide) (Figure 1) are used as antimalarial drugs $[1,2]$. Synergism between PYR and SUL is explained by inhibition of two steps in an essential metabolic pathway. The two steps involved are the utilization of $\mathrm{p}$-amino benzoic acid for the synthesis of dihydropteroic acid, which is catalysed by dihydropteroate synthase and inhibited by SUL and the reduction of dihydrofolate to tetrahydrofolate, which is catalysed by dihydrofolate reductase and inhibited by PYR [3].

Individual PYR and SUL as well as combination of both are officially recognized in the Pharmacopoeia. The Pharmacopoeia describes a titrimetric method for determination of PYR and SUL in their individual tablet formulation and high-performance liquid chromatography (HPLC) for tablet formulation. The other reported methods for quantification of PYR and SUL individually or in combination with other drugs from dosage form or in biological fluids include various analytical methods such as spectrophotometry $[4,5]$, HPLC with UV [6-12], HPLC with MS [13], supercritical fluid chromatography (SFC) [14], and spectrofluorimetry [15].

Nowadays, HPTLC has become a routine analytical technique due to its advantages of reliability in quantitation of analytes in micro and even in nanogram levels and cost effectiveness (lesser amount of mobile phase). There has been no published report of simultaneous HPTLC quantification of PYR and SUL in bulk drugs or in pharmaceutical dosage form. A method has therefore been established and validated in accordance with ICH guidelines [16].

\section{Experimental}

2.1. Materials, Reagents and Solutions. Working standards of pharmaceutical grade PYR and SUL were obtained as generous gift from Medopharm Pharmaceuticals, Karnataka, 


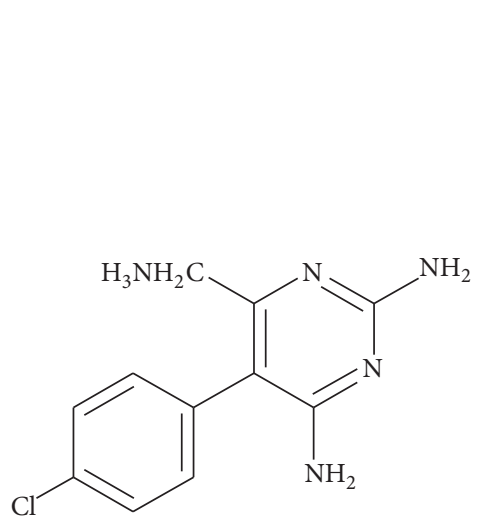

(a)

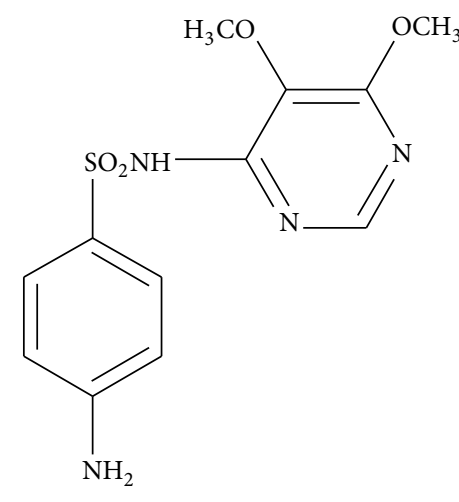

(b)

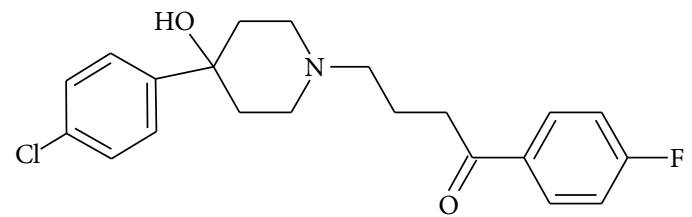

(c)

FIGURE 1: The chemical structure of (a) pyrimethamine, (b) sulphadoxine, and (c) haloperidol (IS).

India. Internal standard haloperidol (IS) was obtained from Intas Pharmaceuticals Ltd., Gujarat, India. All chemicals were of AR grade from Merck Chemicals, India. Combined tablet dosage forms were procured from the local market (labeled to contain PYR $25 \mathrm{mg}$ and SUL $500 \mathrm{mg}$ per tablet).

Stock solutions $(1.0 \mathrm{mg} / \mathrm{mL})$ of compounds were prepared by dissolving $25 \mathrm{mg}$ each PYR, IS, and SUL standards individually into a $25 \mathrm{~mL}$ volumetric flask using methanol. A mixture of the drugs was prepared by transferring appropriate aliquots from standard stock solutions, diluting to volume with methanol to furnish concentration of $40 \mu \mathrm{g} / \mathrm{mL}$ PYR, $100 \mu \mathrm{g} / \mathrm{mL}$ IS, and $800 \mu \mathrm{g} / \mathrm{mL}$ of SUL. The concentration was fixed taking into account the proportion in which PYR and SUL are present together in tablet formulation (1:20 ratio).

2.2. Chromatography. TLC aluminium plates precoated with silica gel $60 \mathrm{~F}_{254}(10 \times 10 \mathrm{~cm}, 250 \mu \mathrm{m}$ thickness $)$ were obtained from Merck chemicals, Mumbai, India. Samples were applied as bands $10 \mathrm{~mm}$ wide and $6 \mathrm{~mm}$ apart, first application $x$-axis $10 \mathrm{~mm}$ and $y$-axis $6 \mathrm{~mm}$, by use of a Linomat 5 (CAMAG, Switzerland) sample applicator, equipped with a $100 \mu \mathrm{L}$ syringe, and the constant application rate was $150 \mathrm{~nL} \mathrm{~s}^{-1}$. Plates were developed to different distances in a $10 \times 10$ glass chamber (Twin Trough) previously saturated with mobile phase vapor for $15 \mathrm{~min}$ at room temperature $\left(30^{\circ} \mathrm{C}\right)$. Good separation and well-developed peaks were obtained using chloroform-n-butanol-acetone $(6: 1.5: 2, \mathrm{v} / \mathrm{v} / \mathrm{v})$ as a mobile phase. The chromatogram was run over a distance of $80 \mathrm{~mm}$. After development, the plates were dried in an oven at $60^{\circ} \mathrm{C}$. Densitometric scanning was performed with a TLC scanner equipped with winCATS 1.4.2 software (Camag, Switzerland) in reflectance absorbance mode. The slit dimensions were $6 \mathrm{~mm} \times 0.30 \mathrm{~mm}$, and the scanning speed was $20 \mathrm{~mm} \mathrm{~s}^{-1}$. Plates were scanned at $254 \mathrm{~nm}$ which was selected experimentally on the basis of distinctive absorption spectra of the compounds between 200 and $400 \mathrm{~nm}$.

2.3. Method Validation. The method was validated in accordance with ICH guidelines on the validation of analytical methods.
2.4. Linearity and Sensitivity. For preparation of calibration plot, $2.5-12.5 \mu \mathrm{L}$ of standard solution containing $40 \mu \mathrm{g} / \mathrm{mL}$ of PYR, $100 \mu \mathrm{g} / \mathrm{mL}$ of IS, and $800 \mu \mathrm{g} / \mathrm{mL}$ of SUL were applied to plate to furnish a concentration of $100-500 \mathrm{ng} / \mathrm{band}$ PYR, 250-1250 ng/band IS, and 2000-10000 ng/band SUL, respectively. Each standard was analyzed in five replicates and peak areas were recorded. Calibration plots were constructed separately by plotting mean R.R.F (Relative retention factor, peak area ratio of PYR or SUL to IS) against respective concentration of PYR and SUL. The data were best fitted by a linear equation $m x+b=y$. The limit of detection (LOD) and quantification (LOQ) were calculated based on the following equations:

$$
\begin{aligned}
& \mathrm{LOD}=\frac{3.3 \times N}{B}, \\
& \mathrm{LOQ}=\frac{10 \times N}{B},
\end{aligned}
$$

where $N$ is the standard deviation of the peak areas of the drugs $(n=5)$ taken as a measure of noise, and $B$ is the slope of corresponding calibration curve.

2.5. Precision. The intraday and interday precision was evaluated by injecting three different aliquots of mixed standard solution in triplicate in a day and on three consecutive days (fresh samples were prepared every day). For each solution, triplicate analysis was performed by a single analyst at the same time under same conditions.

2.6. Accuracy. The accuracy of the method was ascertained by performing recovery studies in triplicate using standard addition method. Accurately known amounts of samples were added to a known amount of preanalyzed tablet powder, and the powder was analyzed.

2.7. Robustness. To access the robustness of the method, after introduction of small changes in the mobile phase composition $( \pm 0.1 \mathrm{~mL}$ for each component), the effects on the results were examined in triplicate. Two different distances, 


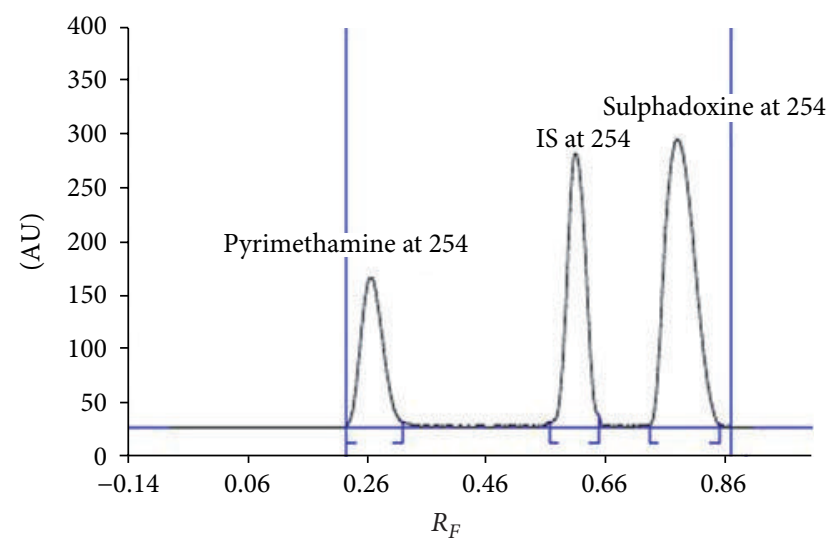

FIGURE 2: Densitogram obtained from PYR $\left(R_{F} 0.27\right)$, IS $\left(R_{F} 0.63\right)$, and SUL $\left(R_{F} 0.75\right)$ at $254 \mathrm{~nm}$.

namely 8 , and $9 \mathrm{~cm}$ were tried. The time from spotting to chromatography was also varied.

2.8. Specificity. Specificity is the ability to unequivocally identify the analyte of interest among other compounds expected to be present, for example, impurities, degradation products, and matrix components. Forced degradation studies were carried out in accordance with $\mathrm{ICH}$ guidelines. Sample solution was prepared after exposing tablet powder equivalent to $25 \mathrm{mg}$ PYR and 500 SUL to different conditions for 24 hours, for example

(i) $50^{\circ} \mathrm{C}$ after addition of $1.0 \mathrm{~mL} 0.1 \mathrm{M}$ Hydrochloric acid,

(ii) $50^{\circ} \mathrm{C}$ after addition of $1.0 \mathrm{~mL} 0.1 \mathrm{M}$ Sodium hydroxide,

(iii) $50^{\circ} \mathrm{C}$ after addition of $1.0 \mathrm{~mL} 3.0 \%$ Hydrogen peroxide,

(iv) $60^{\circ} \mathrm{C}$, and

(v) in a UV cabinet at $265 \mathrm{~nm}$.

2.9. Analysis of Marketed Tablet Dosage Form. The application of developed method was evaluated to determine the amounts of PYR and SUL in their marketed combined tablet dosage form with label claims of $25 \mathrm{mg}$ PYR and $500 \mathrm{mg}$ SUL. Twenty tablets were weighed and the average weight was calculated. A quantity of tablet powder equivalent to $5 \mathrm{mg}$ PYR and $100 \mathrm{mg}$ SUL was weighed and transferred to $100 \mathrm{~mL}$ volumetric flask. The powder was dissolved in methanol and diluted to volume with same solvent to furnish a solution containing $50 \mu \mathrm{g} / \mathrm{mL}$ PYR and $1000 \mu \mathrm{g} / \mathrm{mL}$ SUL. The solution was filtered through Whatman filter paper No. 41, then $10 \mathrm{~mL}$ of solution was transferred to a $25 \mathrm{~mL}$ volumetric flask. To this $2.5 \mathrm{~mL}$ of standard stock solution $(1.0 \mathrm{mg} / \mathrm{mL})$ of IS was added and diluted to $25 \mathrm{~mL}$ with methanol to furnish a solution containing $20 \mu \mathrm{g} / \mathrm{mL}$ PYR, $100 \mu \mathrm{g} / \mathrm{mL}$ IS and $400 \mu \mathrm{g} / \mathrm{mL}$ SUL. The plate was activated and $10 \mu \mathrm{L}$ of sample solution was spotted and analyzed. Quantification was done using relative retention factor (R.R.F) for PYR and

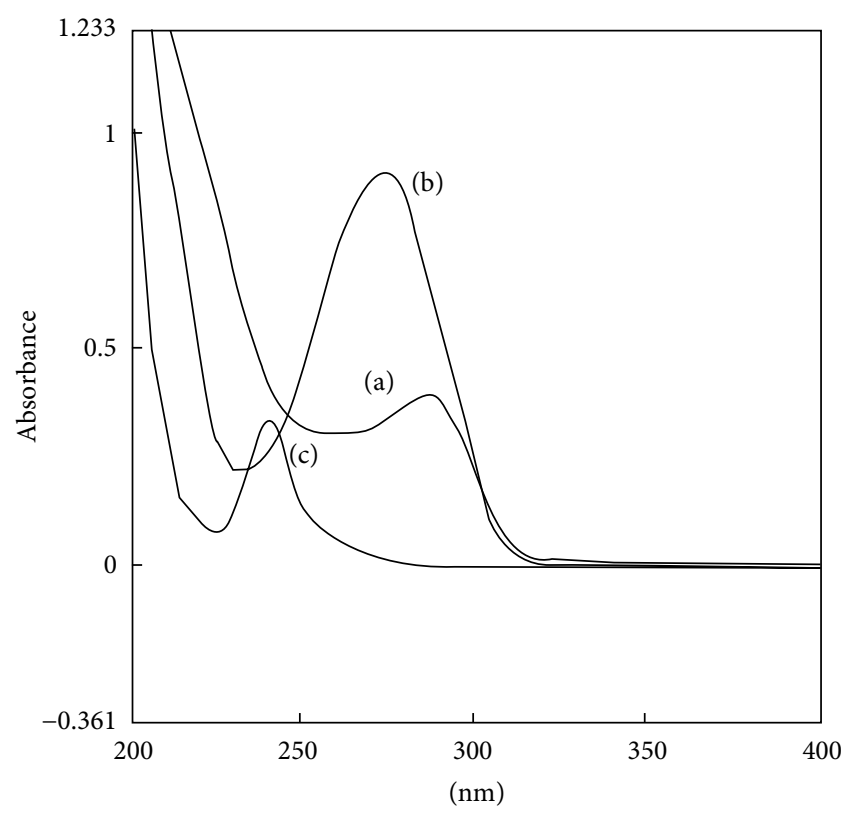

FIgURE 3: Typical overlaid absorption spectra of (a) PYR: pyrimethamine, (b) SUL: sulphadoxine, and (c) IS: haloperidol. The wavelength selected for analysis was $254 \mathrm{~nm}$.

TABLE 1: Results from method validation.

\begin{tabular}{lcc}
\hline \multirow{2}{*}{ Property } & \multicolumn{2}{c}{ Value } \\
& PYR & SUL \\
\hline Range (ng per spot) & $100-500$ & $2000-10000$ \\
Correlation coefficient $\left(r^{2}\right)$ & 0.9998 & 0.9987 \\
Slope & 12.128 & 3.421 \\
Limit of detection (ng per band) & 14.15 & 58.37 \\
Limit of quantification (ng per band) & 43.07 & 152.26 \\
Specificity & Specific & Specific \\
System suitability, RSD (\%) & 0.93 & 1.20 \\
\hline
\end{tabular}

PYR: pyrimethamine; SUL: sulphadoxine.

SUL. The procedure was repeated five times for analysis of homogenous samples.

\section{Results and Discussion}

3.1. Method Development. The composition of the mobile phase for the development of chromatographic method was optimized by testing different solvent mixtures of varying polarity. Use of chloroform-methanol and saturation time of $15 \mathrm{~min}$ gave necklace effect. So, chloroform-n-butanolacetone $(6: 1.5: 2, \mathrm{v} / \mathrm{v} / \mathrm{v})$ and toluene-ethyl acetate-methanol $(8: 2: 0.3, \mathrm{v} / \mathrm{v} / \mathrm{v})$ was tried. These conditions were found to be satisfactory. But better resolution were obtained using chloroform-n-butanol-acetone $(6: 1.5: 2, \mathrm{v} / \mathrm{v} / \mathrm{v})$. It gave symmetric, well-resolved spots with $R_{F}$ values of PYR (0.27), IS (0.63), and SUL (0.75) as shown in Figure 2. Peak integration of both drugs was very small when HPTLC plates were scanned after drying at room temperature. So, plates were dried in an oven at $60^{\circ} \mathrm{C}$ for different time intervals. From 
TABLE 2: Intraday and interday precision data for PYR and SUL $(n=3)$.

\begin{tabular}{|c|c|c|c|c|c|}
\hline \multirow{2}{*}{ Drug } & \multirow{2}{*}{$\begin{array}{c}\text { Quantity } \\
\text { (ng) per band }\end{array}$} & \multicolumn{2}{|c|}{ Intraday precision } & \multicolumn{2}{|c|}{ Interday precision } \\
\hline & & Mean R.R.F \pm SD & RSD (\%) & Mean R.R.F \pm SD & RSD (\%) \\
\hline \multirow{3}{*}{ PYR } & 100 & $0.123 \pm 0.0012$ & 0.98 & $0.142 \pm 0.0021$ & 1.47 \\
\hline & 200 & $0.171 \pm 0.0014$ & 0.82 & $0.194 \pm 0.0019$ & 0.98 \\
\hline & 300 & $0.241 \pm 0.0013$ & 0.54 & $0.254 \pm 0.0023$ & 0.91 \\
\hline \multirow{3}{*}{ SUL } & 2000 & $1.152 \pm 0.0141$ & 1.22 & $1.172 \pm 0.0214$ & 1.83 \\
\hline & 3000 & $1.253 \pm 0.0125$ & 0.99 & $1.260 \pm 0.0207$ & 1.64 \\
\hline & 4000 & $1.421 \pm 0.0135$ & 0.95 & $1.443 \pm 0.0231$ & 1.60 \\
\hline
\end{tabular}

PYR: pyrimethamine; SUL: sulphadoxine.

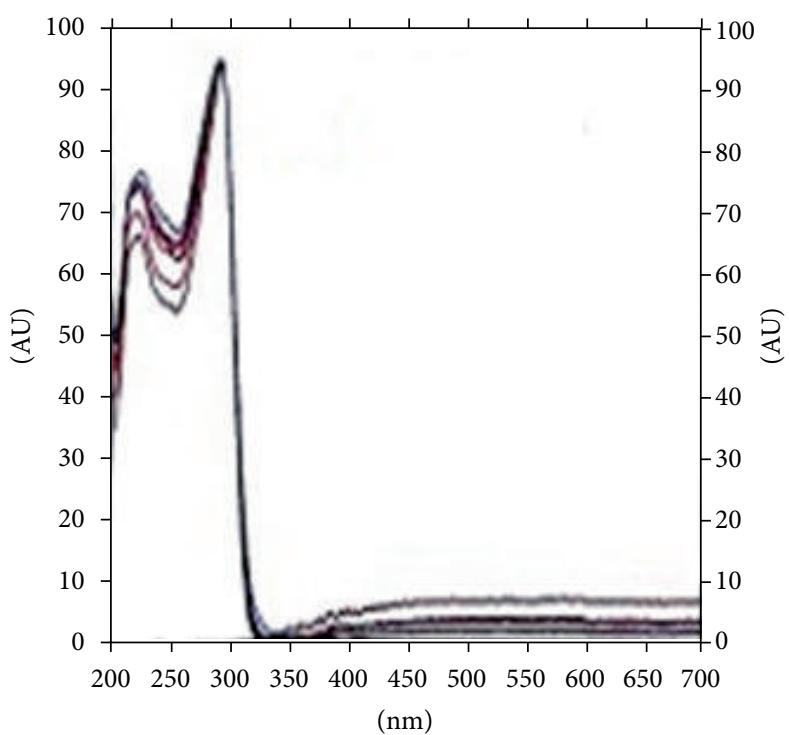

(a)

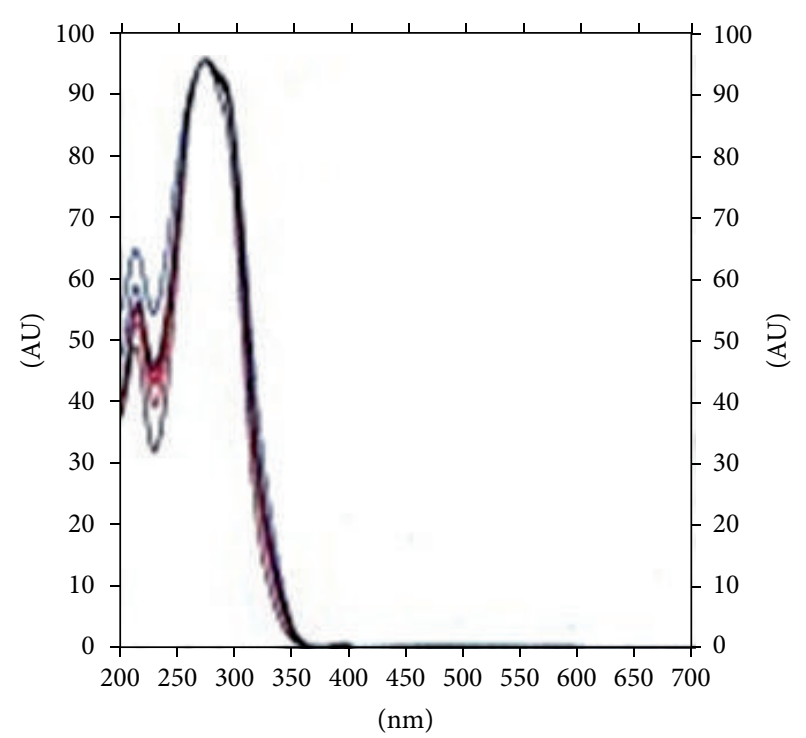

(b)

FIGURE 4: Peakpurity spectra of (a) pyrimethamine, (b) sulphadoxine.

overlain spectra (Figure 3), it was observed that all the three drugs, PYR, SUL, and IS, exhibited strong absorbance at $254 \mathrm{~nm}$ which was selected as analytical wavelength for further analysis.

3.2. Validation. Densitogram obtained shows no interference between peaks or from other constituents originating from the excipient substances of tablets. It can also be assumed from peak purity spectra (Figure 4) that the method is specific for these analytes which enables reliable results to be obtained. The linearity ranges from 100 to $500 \mathrm{ng}$ per band for PYR and from 2000 to 10000 per band for SUL. The correlation coefficients (from 0.9998 to 0.9987 ) and regression data prove linearity of the method within the concentration range examined. The LODs were 14.15 and 58.37 ng per band for PYR and SUL, respectively; the respective LOQs were 43.07 and 152.26 ng per band (Table 1). The relative standard deviation (\%RSD) for the analysis of three replicates depicts good precision, that is, $<2 \%$ (Table 2 ). The recovery of the drugs was 98.12 to $101.24 \%$ (Table 3 ). The results indicated that the method enables accurate analysis of drugs in the tablet dosage form. The results of specificity studies showed that PYR and SUL are stable when exposed to different stress conditions. No significant deviation of $R_{F}$ values or variation of assay values were observed. Densitograms obtained from samples stressed under different conditions are given in Figure 5. Quantitative analysis of the drugs in the pharmaceutical dosage form (Table 4) was characterized by satisfactory precision and accuracy, and the amounts determined did not deviate from the declared values. The method was shown to be robust (Table 5) to changes in solvent composition, development distance, and time of spotting to chromatography.

\section{Conclusion}

A relatively fast, simple, and accurate method has been established for analysis of PYR and SUL in pharmaceutical preparations. Statistical analysis proves that the method is repeatable and selective for the analysis of PYR and SUL. Its advantages are low cost of reagents, speed, and simplicity of sample treatment, satisfactory precision, and accuracy. 
TABLE 3: Accuracy studies of PYR and SUL $(n=3)$.

\begin{tabular}{|c|c|c|c|c|c|}
\hline Drug & Initial amount (mg) & Fortified amount (mg) & Total amount (mg) & Recovery (\%) & RSD (\%) \\
\hline \multirow{3}{*}{ PYR } & \multirow{3}{*}{25} & 25 & 50 & 100.73 & 0.62 \\
\hline & & 50 & 75 & 99.32 & 0.42 \\
\hline & & 100 & 125 & 98.12 & 1.32 \\
\hline \multirow{3}{*}{ SUL } & \multirow{3}{*}{500} & 25 & 525 & 98.62 & 0.13 \\
\hline & & 50 & 550 & 101.24 & 0.73 \\
\hline & & 100 & 600 & 99.71 & 1.12 \\
\hline
\end{tabular}

PYR: pyrimethamine; SUL: sulphadoxine.

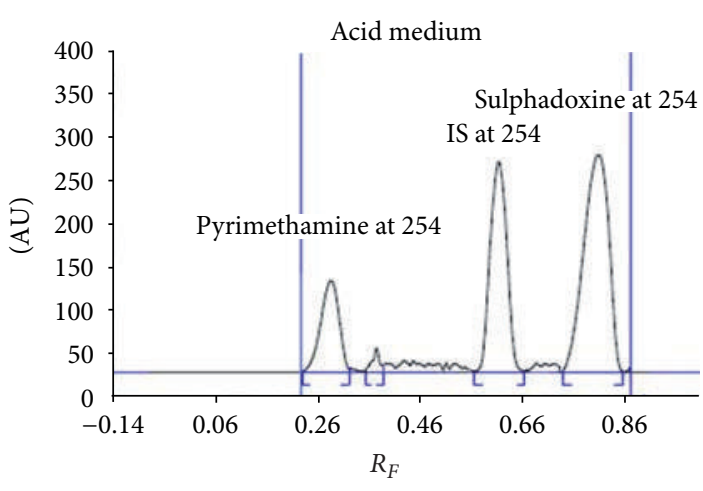

(a)

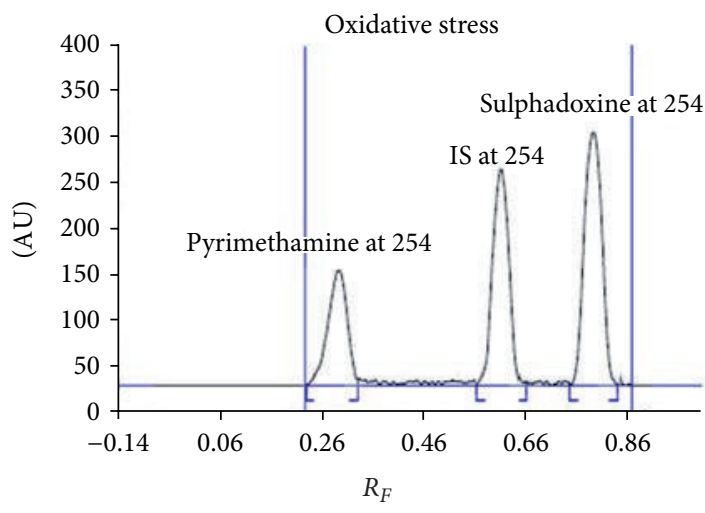

(c)

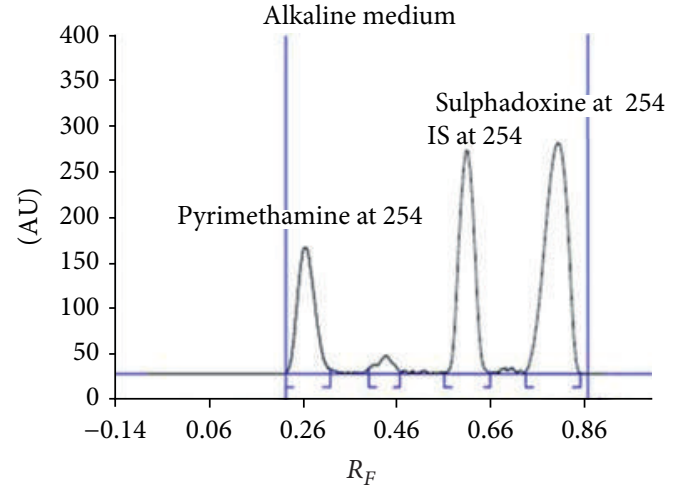

(b)

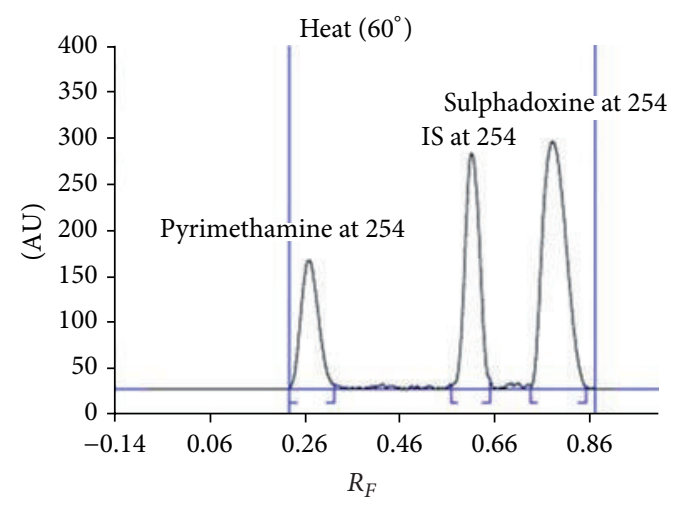

(d)

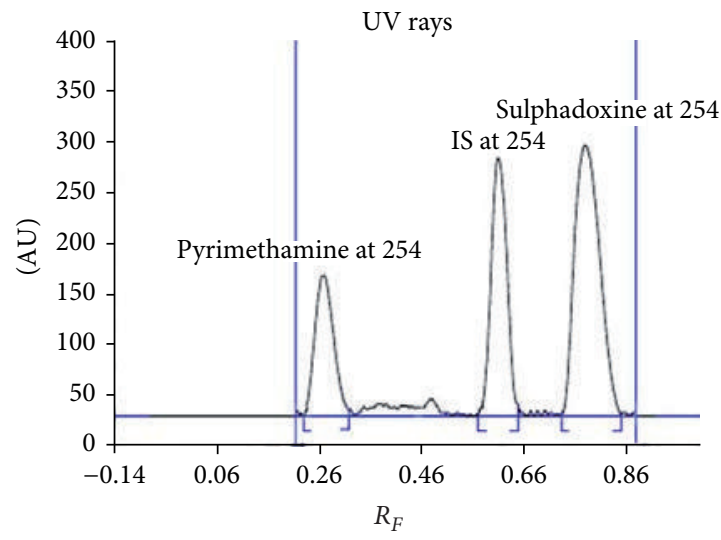

(e)

FIGURE 5: Densitograms obtained after stress testing under different conditions. 
TABLE 4: Results from analysis of pharmaceutical formulation $(n=$ $3)$.

\begin{tabular}{lccc}
\hline Drug & Label claim $(\mathrm{mg})$ & Drug content $(\%)$ & RSD $(\%)$ \\
\hline PYR & 25 & 99.56 & 0.63 \\
SUL & 500 & 101.87 & 0.97
\end{tabular}

PYR: pyrimethamine; SUL: sulphadoxine.

TABLE 5: Results of robustness testing $(n=3)$.

\begin{tabular}{lcccc}
\hline \multirow{2}{*}{ Condition } & \multicolumn{2}{c}{ Recovery (\%) } & \multicolumn{2}{c}{ RSD (\%) } \\
& PYR & SUL & PYR & SUL \\
\hline Mobile phase composition & & & & \\
$\quad 5.9: 1.6: 2$ & 98.71 & 101.31 & 0.86 & 0.32 \\
$6: 1.4: 2.1$ & 99.32 & 100.86 & 0.71 & 0.71 \\
$\quad 6.1: 1.5: 1.9$ & 98.65 & 99.23 & 1.13 & 0.31 \\
Development distance [cm] & & & & \\
$\quad 8$ & 98.12 & 99.73 & 1.32 & 0.82 \\
$\quad 9$ & 99.31 & 100.52 & 1.51 & 0.91 \\
Time spotting to chromatography & & & & \\
$\quad 10$ min & 100.71 & 101.13 & 0.47 & 0.71 \\
\hline
\end{tabular}

PYR: pyrimethamine; SUL: sulphadoxine.

\section{References}

[1] The Indian Phamacopoeia, The Indian Pharmacopoeia Commission, vol. 3, NISCAIR Press, New Delhi, India, 5th edition, 2007.

[2] United States Pharmacopoeia/The National Formulary (USP31/NF26), United States Pharmacopoeial Convention, Rockville, Md, USA, 2008.

[3] "The Pharmcological basis of therapeutics, Goodman and Gilman's, Joel. G. Hardman, Lee. E. Limbird," 1080-81.

[4] J. O. Onah and J. E. Odeiani, "Simultaneous spectrophotometric determination of sulfadoxine and pyrimethamine in pharmaceutical formulations," Journal of Pharmaceutical and Biomedical Analysis, vol. 30, no. 3, pp. 851-857, 2002.

[5] M. D. Green, D. L. Mount, and G. D. Todd, "Determination of sulfadoxine concentrations in whole blood using $\mathrm{C}_{18}$ solidphase extraction, sodium dodecyl sulfate and dimethylaminocinnamaldehyde," Analyst, vol. 120, no. 10, pp. 2623-2626, 1995.

[6] M. A. AtemnKeng, B. Chimanuka, and J. Plaizier-Vercamman, "Quality evaluation of chloroquine, quinine, sulfadoxine-pyrimethamine and proguanil formulations sold on the market in East Congo DR ", Clinical Pharmacy and Therapeutics, vol. 32, no. 2, pp. 123-132, 2007.

[7] J. J. Berzas Nevado, G. Castañeda Peñalvo, and F. J. Guzmán Bernardo, "Simultaneous determination of sulfaquinoxaline, sulfamethazine and pyrimethamine by liquid chromatography," Journal of Chromatography A, vol. 870, no. 1-2, pp. 169-177, 2000.

[8] J. Eljjaschewitsch, J. Padberg, and D. Schurmann, "Highperformance liquid chromatography determination of pyrimethamine, dapsone, monoacetyldapsone, sulfadoxine, and $\mathrm{N}$-acetyl-sulfadoxine after rapid solid-phase extraction," Theraepeutic Drug Monitoring, vol. 18, pp. 592-597, 1996.

[9] H. Astier, C. Renard, V. Cheminel et al., "Simultaneous determination of pyrimethamine and sulphadoxine in human plasma by high-performance liquid chromatography after automated liquid-solid extraction," Journal of Chromatography B, vol. 698, no. 1-2, pp. 217-223, 1997.

[10] Y. Bergquist and M. Eriksso, "Simultaneous determination of pyrimethamine and sulphadoxine in human plasma by highperformance liquid chromatography," Transactions of the Royal Society of Tropical Medicine and Hygiene, vol. 79, pp. 297-301, 1985.

[11] C. Midsko, "High-performance liquid chromatographic assay of pyrimethamine, sulfadoxine and its $\mathrm{N}^{4}$-acetyl metabolite in serum and urine after ingestion of suldox," Journal of Chromatography B: Biomedical Sciences and Applications, vol. 308, pp. 217-227, 1984.

[12] M. Edste, "Quantification of antimalarial drugs : I. Simultaneous measurement of sulphadoxine, $\mathrm{N}_{4}$-acetylsulphadoxine and pyrimethamine in human plasma," Journal of Chromatography, vol. 305, pp. 502-507, 1984.

[13] U. Koesukwiwat, S. Jayanta, and N. Leepipatpiboon, "Validation of a liquid chromatography-mass spectrometry multi-residue method for the simultaneous determination of sulfonamides, tetracyclines, and pyrimethamine in milk," Journal of Chromatography A, vol. 1140, no. 1-2, pp. 147-156, 2007.

[14] S. I. Bhoir, I. C. Bhoir, A. M. Bhagwat, and M. Sundaresan, "Determination of sulfadoxine in human blood plasma using packed-column supercritical fluid chromatography," Journal of Chromatography B, vol. 757, no. 1, pp. 39-47, 2001.

[15] O. R. Idowu and O. A. Dada, "Simple and sensitive spectrofluorimetric determination of pyrimethamine in biological fluids," Analytica Chimica Acta, vol. 169, pp. 361-365, 1985.

[16] ICH Q2, (R1), Validation of Analytical Procedures: Text and Methodology CPMP/ICH/381/95, Geneva, Switzerland, 1995. 

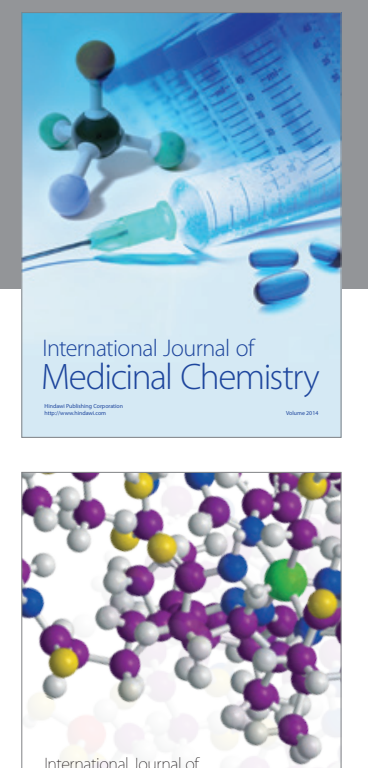

\section{Carbohydrate} Chemistry

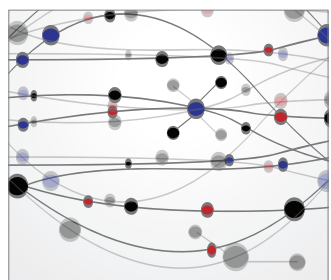

The Scientific World Journal
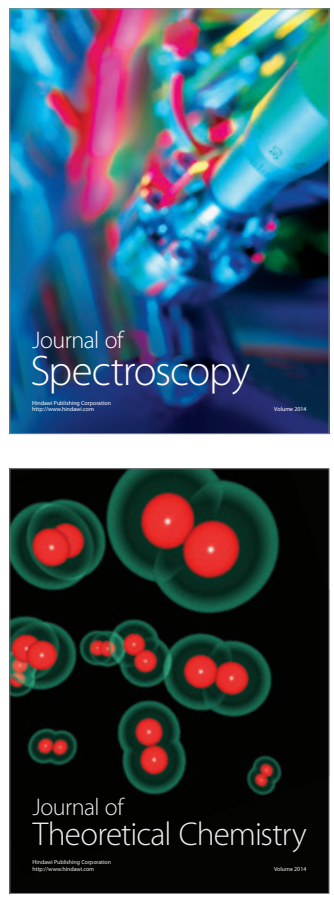
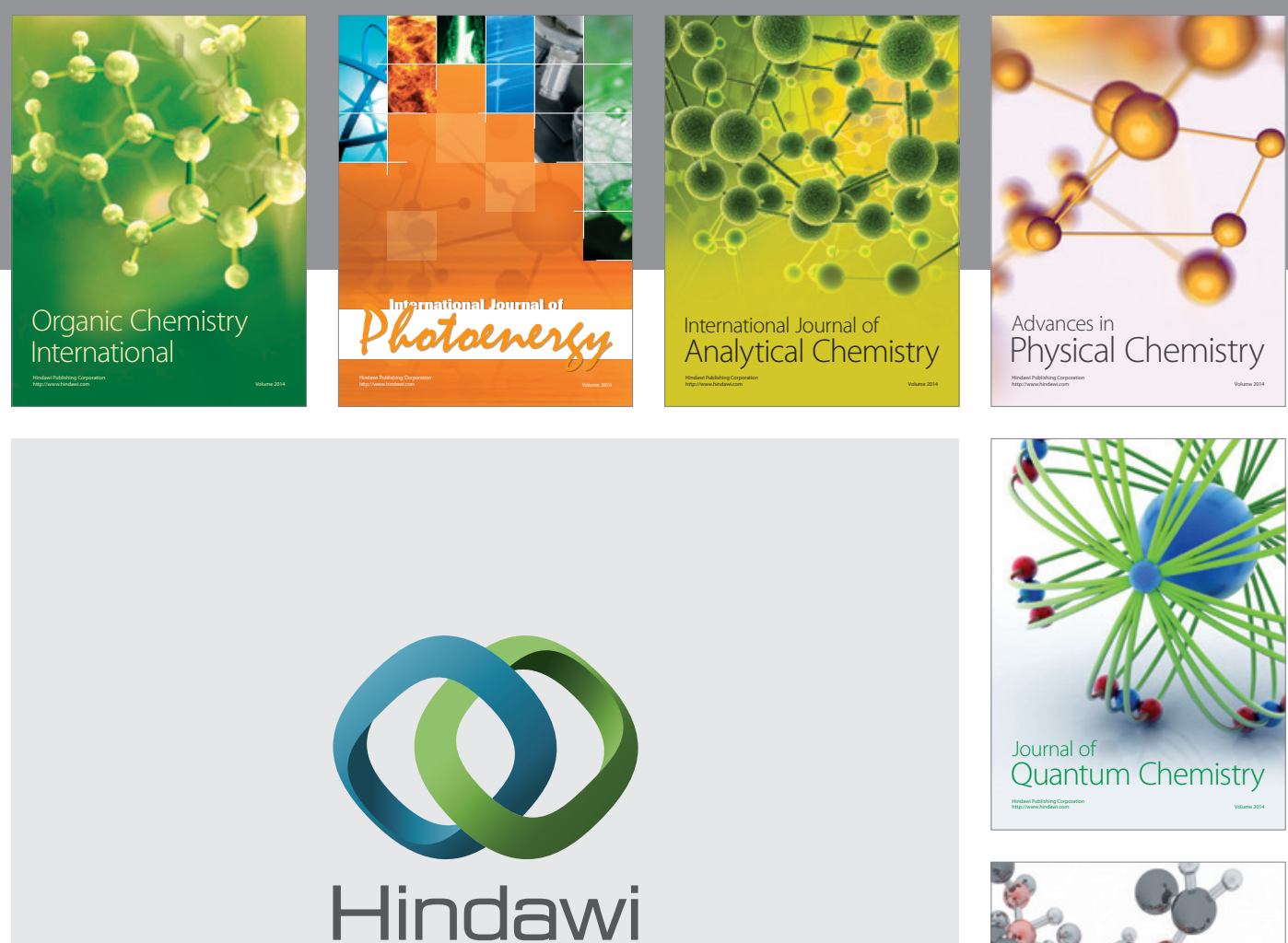

Submit your manuscripts at

http://www.hindawi.com

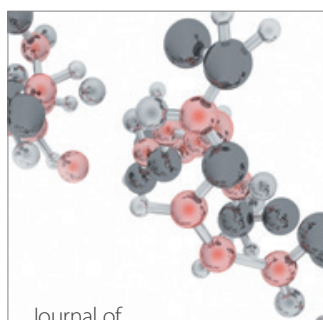

Analytical Methods

in Chemistry

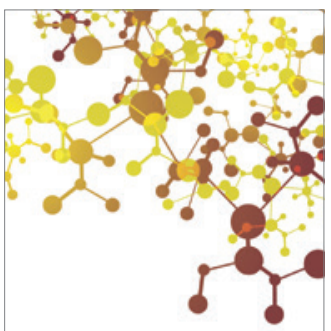

Journal of

Applied Chemistry

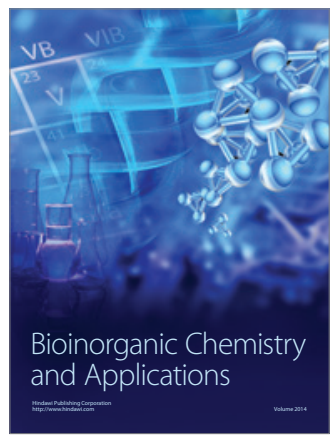

Inorganic Chemistry
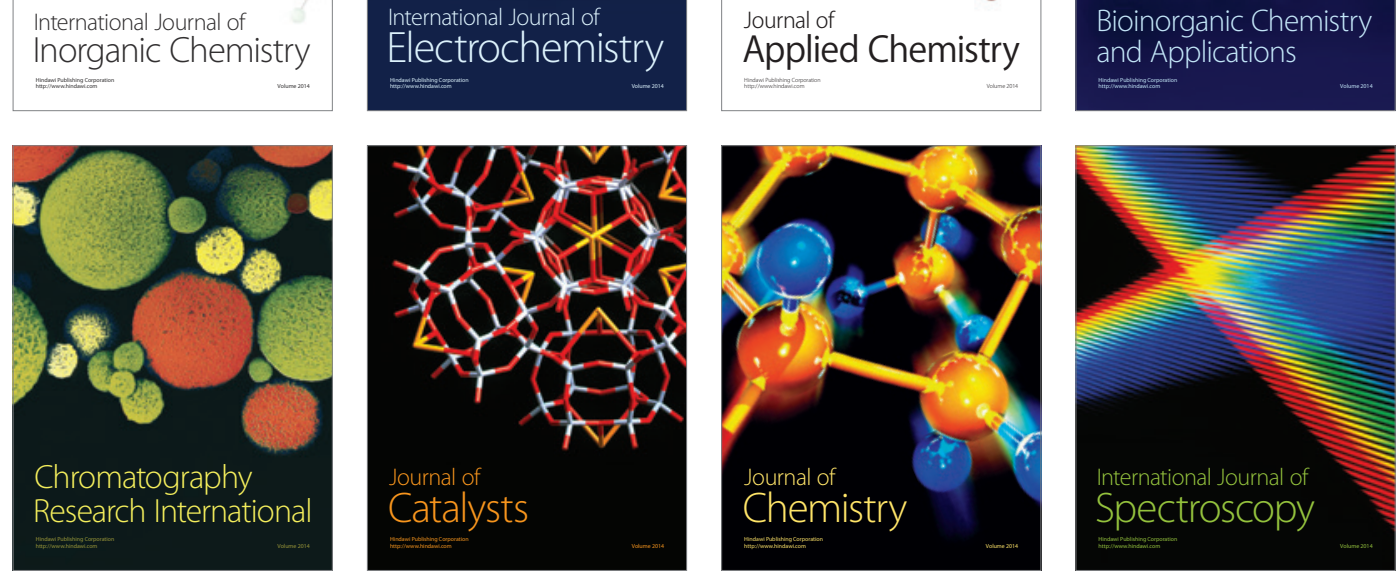